\title{
Deep RNA sequencing analysis of syncytialization-related genes during BeWo cell fusion
}

\begin{abstract}
Ru Zheng ${ }^{1,4, *}$, Yue Li ${ }^{2, *}$, Huiying Sun ${ }^{3,4, *}$, Xiaoyin Lu ${ }^{1,4}$, Bao-Fa Sun ${ }^{3}$, Rui Wang ${ }^{1,4}$, Lina Cui ${ }^{1,4}$, Cheng Zhu' ${ }^{1}$, Hai-Yan Lin ${ }^{1}$ and Hongmei Wang ${ }^{1}$

${ }^{1}$ State Key Laboratory of Stem Cell and Reproductive Biology, Institute of Zoology, Chinese Academy of Sciences, Beijing, People's Republic of China, ${ }^{2}$ Peking University Third Hospital, Center of Reproductive Medicine, Department of Obstetrics and Gynecology, Beijing, People's Republic of China, ${ }^{3}$ Key Laboratory of Genomic and Precision Medicine, Collaborative Innovation Center of Genetics and Development, CAS Center for Excellence in Molecular Cell Science, Beijing Institute of Genomics, Chinese Academy of Sciences, Beijing, People's Republic of China and ${ }^{4}$ University of Chinese Academy of Sciences, Beijing, People's Republic of China
\end{abstract}

Correspondence should be addressed to H-Y Lin; Email: linhy@ioz.ac.cn

*(R Zheng, Y Li and H Sun contributed equally to this work)

\begin{abstract}
The syncytiotrophoblast (STB) plays a key role in maintaining the function of the placenta during human pregnancy. However, the molecular network that orchestrates STB development remains elusive. The aim of this study was to obtain broad and deep insight into human STB formation via transcriptomics. We adopted RNA sequencing (RNA-Seq) to investigate genes and isoforms involved in forskolin (FSK)-induced fusion of BeWo cells. BeWo cells were treated with $50 \mu \mathrm{M}$ FSK or dimethyl sulfoxide (DMSO) as a vehicle control for 24 and $48 \mathrm{~h}$, and the mRNAs at 0,24 and $48 \mathrm{~h}$ were sequenced. We detected 28,633 expressed genes and identified 1902 differentially expressed genes (DEGs) after FSK treatment for 24 and $48 \mathrm{~h}$. Among the 1902 DEGs, 461 were increased and 395 were decreased at $24 \mathrm{~h}$, whereas 879 were upregulated and 763 were downregulated at $48 \mathrm{~h}$. When the 856 DEGs identified at $24 \mathrm{~h}$ were traced individually at $48 \mathrm{~h}$, they separated into 6 dynamic patterns via a K-means algorithm, and most were enriched in down-even and up-even patterns. Moreover, the gene ontology (GO) terms syncytium formation, cell junction assembly, cell fate commitment, calcium ion transport, regulation of epithelial cell differentiation and cell morphogenesis involved in differentiation were clustered, and the MAPK pathway was most significantly regulated. Analyses of alternative splicing isoforms detected 123,200 isoforms, of which $\mathbf{1 3 7 6}$ were differentially expressed. The present deep analysis of the RNA-Seq data of BeWo cell fusion provides important clues for understanding the mechanisms underlying human STB formation.

Reproduction (2017) 153 35-48
\end{abstract}

\section{Introduction}

Cell-cell fusion is required for several physiological processes, including fertilization, myogenesis and osteoclast formation (Chen \& Olson 2005). In addition to these processes, cell-cell fusion is important for syncytiotrophoblast (STB) formation in the human placenta (Potgens et al. 2004). The placenta is a temporal organ formed only during pregnancy and is critical for fetal development and maternal health. Mononuclear cytotrophoblast cells (CTBs) in placental villi can differentiate to form extravillous trophoblast cells (EVTs), which invade the maternal uterus, or multinucleated STB, the outer layer of placental villi, via cell-cell fusion. STB serves as a barrier between the mother and fetus and functions in gas exchange, nutrient and waste transport and hormone production (Cross et al. 1994). A well-formed STB is important for the establishment and maintenance of a successful pregnancy. Abnormal STB formation may be involved in pre-eclampsia (PE), a human pregnancy complication that affects $3-5 \%$ of all women worldwide and endangers maternal health and fetal development (Gauster et al. 2009).

The differentiation of CTBs into STB in vivo is a dynamic process. Much of our knowledge of the mechanisms underlying syncytialization has come from the identification of the human endogenous retrovirus (HERV) envelope proteins syncytins (Blond et al. 1999, Mi et al. 2000, Blaise et al. 2003). Syncytin-1, encoded by the HERV-W env gene, is a highly fusogenic membrane glycoprotein mediating human trophoblastic cell-cell fusion and can fuse cells expressing the type D retrovirus receptor alanine/serine/cysteine/threonine transporter type 1 and 2 (ASCT1 and ASCT2) (Blond et al. 2000, 
Lavillette et al. 2002). Syncytin-2, encoded by the $H E R V-F R D$ env gene, is another fusogenic protein and its receptor is major facilitator superfamily domain containing 2A (MFSD2A) (Blaise et al. 2003, Esnault et al. 2008). The major transcriptional factor driving the expression of syncytins during syncytialization is glial cell missing-1 (GCM1), which acts downstream of the cAMP/PKA signaling pathway (Yu et al. 2002, Liang et al. 2010). In addition to syncytins, several cytokines and growth factors have been implicated in regulating syncytialization. For example, insulinlike growth factor (IGF) I/II, epidermal growth factor (EGF) and leukemia inhibitory factor (LIF) promote STB formation, whereas transforming growth factor- $\beta$ (TGF- $\beta$ ) and tumor necrosis factor- $\alpha$ (TNF- $\alpha$ ) inhibit the process (Morrish et al. 1987, Leisser et al. 2006, Forbes et al. 2008, Leduc et al. 2012). Moreover, connexin 43 (CX 43), zona occluden-1 (ZO-1), E-cadherin, CD 98, caspase 8, activin-A, peroxisome proliferator-activated receptor-gamma (PPAR- $\gamma$ ) and calponin 3 (CNN3) are also involved in trophoblast cell fusion (Frendo et al. 2003, Dalton et al. 2007b, Pidoux et al. 2010, Shibukawa et al. 2010, Gerbaud et al. 2011, Ruebner et al. 2012). We have previously reported the requirement of furin and nephrin during trophoblast cell-cell fusion (Zhou et al. 2013, Li et al. 2015) and delineated the process of syncytialization by live-cell imaging in vitro (Wang et al. 2014). However, the molecular network regulating STB formation remains unclear.

In this study, to obtain a comprehensive view of human syncytialization, we applied RNA sequencing (RNASeq) to screen gene expression during FSK-induced human placental choriocarcinoma BeWo cell fusion. GO and KEGG analyses were performed to determine the key enriched biological processes and genes. Our results produce a credible and comprehensive evidence for understanding the transcriptional landscape during human syncytialization.

\section{Materials and methods \\ BeWo cell and human primary CTB culture}

BeWo cells were obtained from ATCC (CCL-98) and cultured as previously described (Wang et al. 2014, Li et al. 2015). In brief, BeWo cells were cultured in Ham's F-12K (Kaighn's) (Gibco BRL)/Dulbecco's Modified Eagle Medium (DMEM) supplemented with $10 \%$ fetal bovine serum (FBS), in $5 \%$ $\mathrm{CO}_{2} / 95 \%$ air at $37^{\circ} \mathrm{C}$. BeWo cells were seeded in $60 \mathrm{~mm}$ plastic dishes at approximately $30 \%$ density and were cultured overnight then treated with $50 \mu \mathrm{M}$ FSK (F6886, Sigma-Aldrich) or dimethyl sulfoxide (DMSO) as a vehicle control for $24 \mathrm{~h}$ or $48 \mathrm{~h}$. The samples were harvested at $0 \mathrm{~h}, 24 \mathrm{~h}$ and $48 \mathrm{~h}$ respectively ( $N=3$ per treatment at each time point).

Human primary CTBs were isolated as previously described (Wang et al. 2014). Briefly, the placenta was scissored and digested in $0.125 \%$ trypsin and $0.03 \%$ DNase-I (Sigma) in DMEM. CTBs were separated by discontinuous $5-65 \%$ Percoll (17-0891-09, GE Healthcare Bio-sciences AB) density gradient centrifugation, plated in Iscove's Modified Dulbecco's Medium (IMDM) $\left(2 \times 10^{6}\right.$ cells per $35-\mathrm{mm}$ dish) supplemented with $10 \% \mathrm{FBS}$ and cultured in $5 \% \mathrm{CO}_{2} / 95 \%$ air at $37^{\circ} \mathrm{C}$. Samples were collected at 24-h intervals. CTBs that spontaneously fused in vitro were confirmed by analysis of $\beta$-human chorionic gonadotropin ( $\beta$-hCG).

\section{ELISA of $\beta$-hCG secretion}

Concentrations of secreted $\beta$-hCG from BeWo cells were measured using a $\beta$-hCG ELISA kit (82080, SunBio Biomedical Technology, Beijing, China). Conditioned media were collected at the indicated times and centrifuged at $4000 \mathrm{rpm}$ for $3 \mathrm{~min}$ at $4^{\circ} \mathrm{C}$ to remove cells and debris, and then were stored at $-80^{\circ} \mathrm{C}$. After thawing at room temperature, the media were diluted to 1:300 and assayed for $\beta$-hCG according to the manufacturer's instructions. The experiment was performed in triplicate.

\section{Immunofluorescence}

The immunofluorescence experiments were performed as previously described (Wang et al. 2014, Li et al. 2015). Briefly, cells were fixed, washed and stained with mouse monoclonal E-cadherin antibody (sc-71008, Santa Cruz Biotechnology).

\section{Total RNA extraction, reverse transcription polymerase chain reaction (RT-PCR) and quantitative real-time PCR (qRT-PCR)}

Cells were harvested by TRIzol reagent (Invitrogen). Total RNA was extracted and $2 \mu \mathrm{g}$ were reversely transcribed using SuperScript II Reverse Transcriptase (Invitrogen) according to the manufacturer's instructions. RT-PCR was conducted on an Applied Biosystems Veriti 96 Well Thermal Cycler. Quantitative real-time PCR was performed using the SYBR Premix Ex Taq II (Tli RNaseH Plus) kit (RR820A, Takara Bio) on a Roche LightCycler 480 system. Sequences of all primers used are provided in Supplementary Tables 1 and 5, see section on supplementary data given at the end of this article.

\section{Immunohistochemistry}

The $5-\mu \mathrm{m}$ sections were cut from human first-trimester placental tissues. The immunodetection was performed as previously described (Wang et al. 2014, Li et al. 2015). Briefly, the sections were dewaxed, rehydrated, antigen retrieved, blocked and incubated with primary antibodies against CACNA1S (calcium channel, voltage dependent, L-type, alpha 1S subunit; 22279, Proteintech Group Inc., Wuhan, China), CD9 (20597, Proteintech), MYH9 (myosin, heavy chain 9, non-muscle; 11128, Proteintech), NEO1 (neogenin 1; 20246, Proteintech), TNS1 (tensin 1; 20054, Proteintech) and $\beta$-hCG (ZM-0134, Zhongshan Golden Bridge Corp., Beijing, China) overnight at $4^{\circ}$. The slides were incubated with secondary antibodies and developed with DAB kits (Zhongshan Golden 
Bridge Corp.). Purified immunoglobulins (IgGs) of the corresponding species were included as negative controls.

\section{RNA sequencing}

Total RNA was extracted from $5 \times 10^{6}$ BeWo cells upon 0-, 24- and 48-h FSK or DMSO treatments using TRIzol reagent and dissolved in 30-50 $\mu \mathrm{L}$ DEPC- $\mathrm{H}_{2} \mathrm{O}$. The quality of the RNA samples was evaluated using an Agilent Bioanalyzer 2100, and only intact total RNA was used. $3 \mu \mathrm{g}$ of total RNA were used to construct the mRNA library for Illumina high parallel sequencing using an Illumina TruSeq RNA sample preparation kit (Illumina, CA, USA) according to the manufacturer's protocol. Briefly, poly-A mRNA was selectively hybridized on poly-T coated magnetic beads. The selected poly-A mRNA was then fragmented in a high salt buffer and transcribed to cDNA using reverse transcriptase. After second strand synthesis of the cDNA, the double-stranded DNA was end-repaired, A-tailed and Illumina adapter ligated. Finally, the mRNA-Seq library was constructed via 15 cycles of PCR and sequenced on an Illumina HiSeq 2000 sequencer as paired-end 100 bp reads.

\section{RNA-Seq data processing}

The quality of raw sequencing reads was determined using FastQC software (http://www.bioinformatics.babraham.ac.uk/ projects/fastqc/) and adapters were trimmed by the FASTXToolkit (http://hannonlab.cshl.edu/fastx_toolkit/). After filtering low quality reads and those containing adapters, clean pair end reads of high quality were mapped to a human reference genome (hg19) using Tophat software (V2.0.4), parameter-G was used, $-p$ is 4 and other parameters were default. The reference genome and the annotation for protein-coding genes were downloaded from the Ensembl database (release 72). The Cufflinks software package was used to calculate the expression level of genes. The abundance of each transcript was defined by fragments per kilobase of exon per million fragments mapped (FPKM). Differentially expressed genes (DEGs) were calculated using the EdgeR package. Isoform analysis was executed by Cuffdiff. One part of the Cufflinks package was applied to calculate the reads count and FPKM for each isoform of each gene. Analysis of gene ontology (GO) term enrichment and KEGG pathway prediction were performed on the DAVID

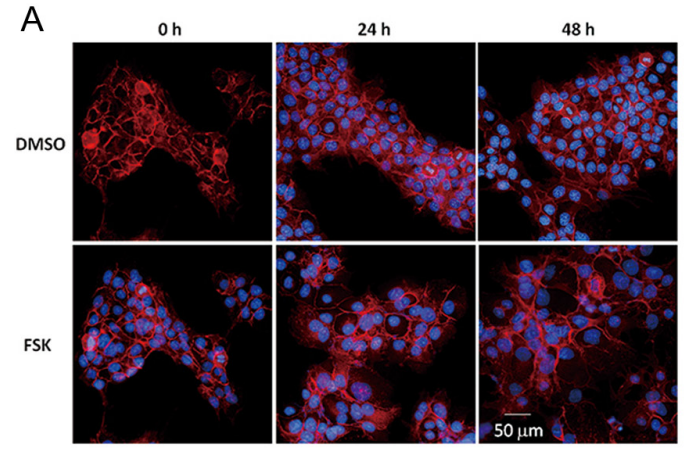

$\mathrm{D}$

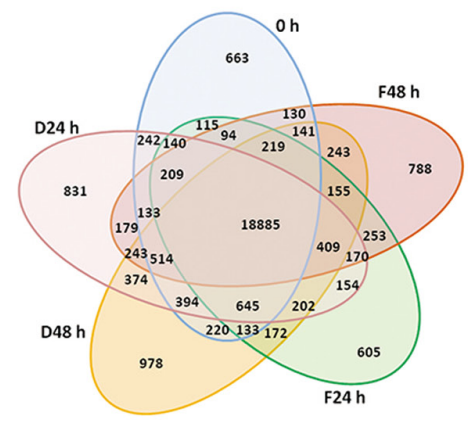

E

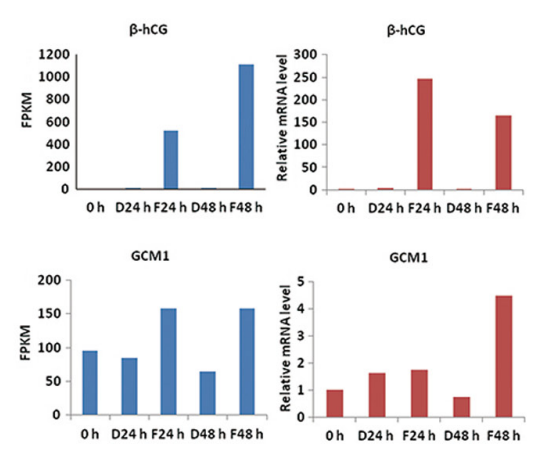

B

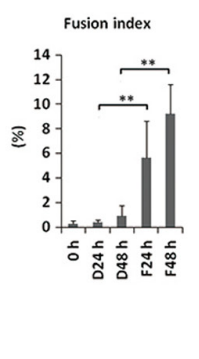

F

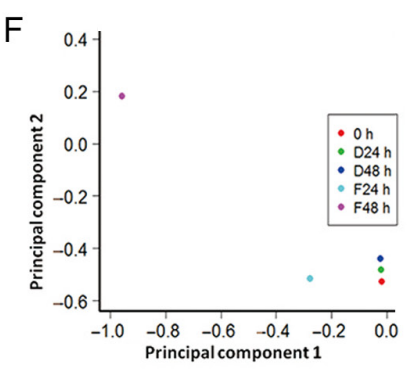

G

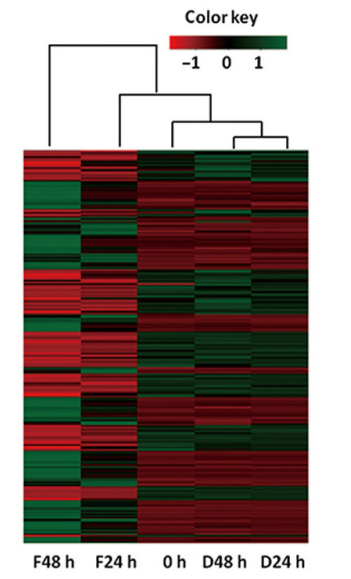

Figure 1 FSK-induced fusion of BeWo cells and RNA-Seq data analyses. (A) Immunofluorescence staining of E-cadherin (red) to outline BeWo cells treated with $50 \mu \mathrm{M}$ FSK for 0,24 and $48 \mathrm{~h}$. DMSO was used as the vehicle control. Nuclei were stained with DAPI (blue). Bar $=50 \mu \mathrm{m}$. (B) The fusion index was determined by analyzing the ratio of multinucleated cells in different samples as visualized by E-cadherin immunostaining. The fusion index was calculated as

$((N-S) / T) \times 100 \%$, where $N$ is the number of nuclei in the syncytia, $S$ is the number of syncytia and $T$ is the total number of nuclei. $* * P<0.01$. (C) Expression levels of secreted $\beta$-hCG during BeWo cell fusion were detected by ELISA. D24h, DMSO treatment for $24 \mathrm{~h}$; D48h, DMSO treatment for $48 \mathrm{~h}$; F24h, FSK treatment for $24 \mathrm{~h}$; F48 h, FSK treatment for $48 \mathrm{~h}$. Data points are shown as the mean \pm S.D. of three independent experiments. ${ }^{* *} P<0.01$. (D) A Venn diagram indicates the overview and overlap of all expressed genes among the five samples. A gene was defined as expressed when FPKM $>0$. (E) The expression patterns of $\beta$-hCG and GCM1 determined by RNA-Seq (left panel) are compared with those measured by qRT-PCR (right panel) for the same samples. (F) PCA shows the similarity of expression patterns among DMSO- and FSK-treated samples. (G) The heatmap shows the hierarchical clustering of the expression patterns of all genes in each sample. 
A

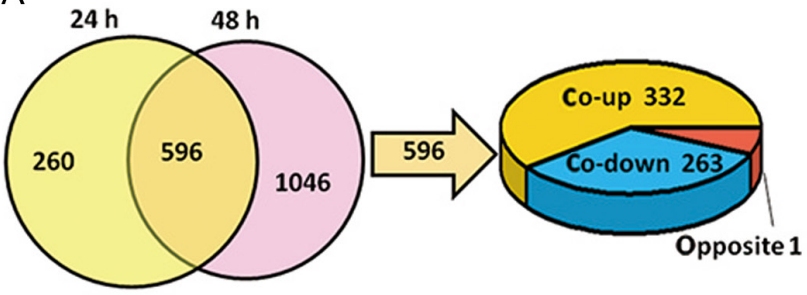

B

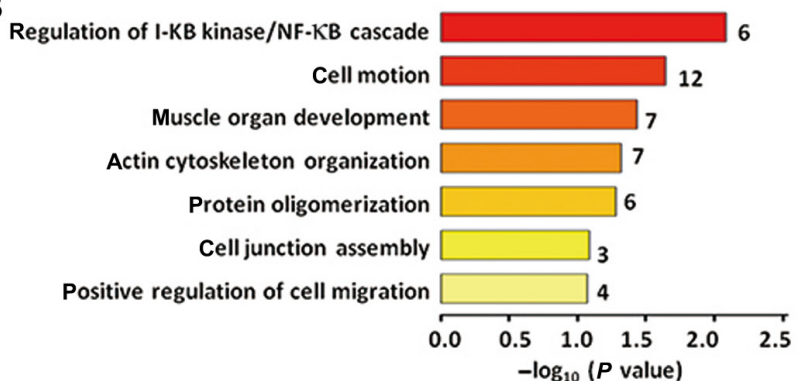

C

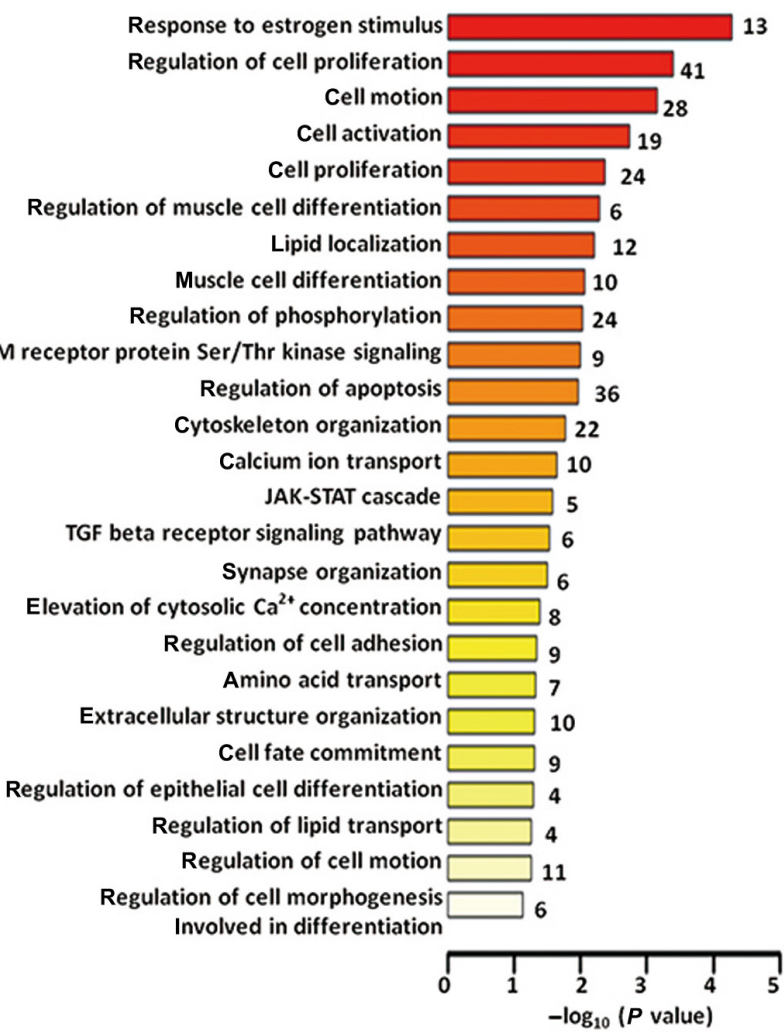

D

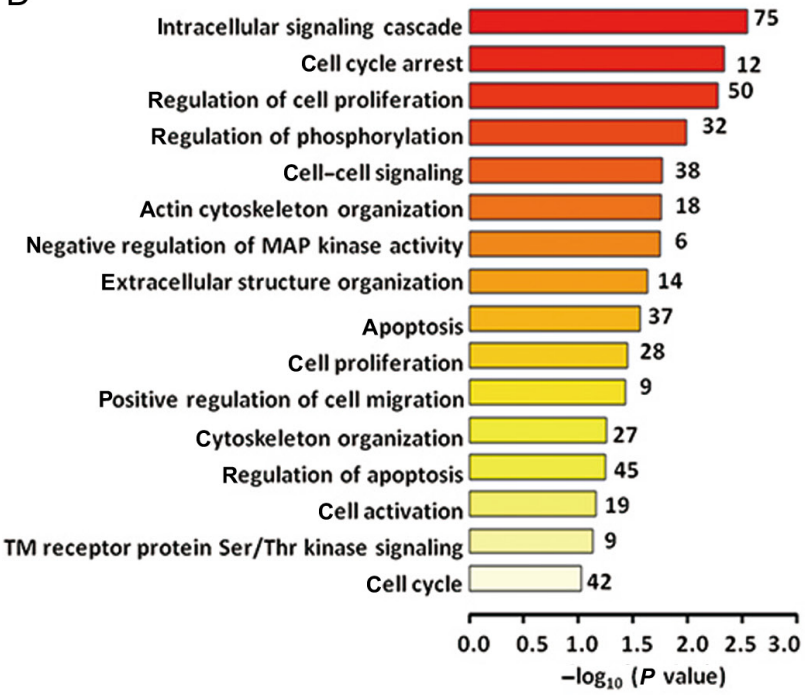

E

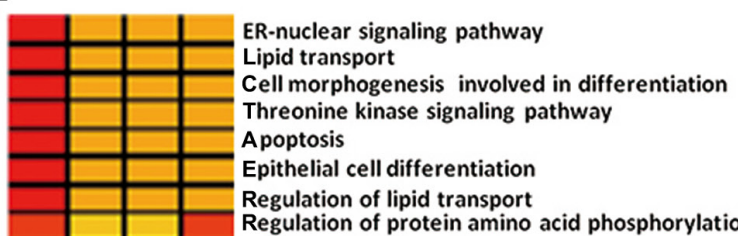

Regulation of protein amino

Muscle cell differentiation

Synapse organization

Ras protein signaling transduction

Extracellular structure organization

Cytoskeleton organization

Regulation of cell adhesion

Cell adhesion

Regulation of cell motion

BMP signaling pathway

Cell death

Cell proliferation

Syncytium formation by plasma membrane fusion

Negative regulation of epithelial cell differentiation

Lipid localization

Collagen metabolic process

Regeneration

Cell junction assembly

Regulation of calcium ion transport

Intracellular signaling cascade

Calcium ion transport

Amino acid transport

Cell-cell signaling

Response to estrogen stimulus

Anti-apoptosis

Regulation of muscle cell differentiation

Inactivation of MAPK activity

Actin cytoskeleton organization

Regulation of cell proliferation

Cell activation

Negative regulation of cell differentiation

Cell motion

Cell migration

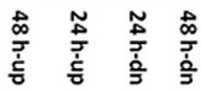

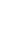


website (https://david.ncifcrf.gov/). We applied DAVID to perform functional annotation of all DEGs and downloaded the result. Then the result was visualized in Cytoscape by the plugin called 'enrichment map'. GO terms were clustered together by similar function under the parameters: $P<0.01$, FDR $q<0.1$, overlap cutoff $>0.5$.

\section{Statistical analysis}

Each experiment was performed in triplicate. The results were presented as the mean \pm S.D. Statistical analyses were performed by one-way ANOVA and $t$-test using the Statistical Package for Social Science (SPSS for Windows package release 10.0; SPSS) as indicated in the 'Results' section and Figure Legends.

\section{Results}

\section{FSK-induced fusion of BeWo cells and RNA-Seq data analysis}

We first established an FSK-induced BeWo cell fusion model. Upon 24- and 48-h FSK $(50 \mu \mathrm{M})$ treatments, the fusion index was significantly elevated, as visualized by immunofluorescence staining for the cell membrane marker E-cadherin (Fig. $1 \mathrm{~A}$ and $\mathrm{B}$ ). Furthermore, the concentration of secreted $\beta$-hCG was also increased in a time-dependent manner (Fig. 1C).

The mRNAs of BeWo cells upon 0-, 24- and 48-h FSK or DMSO treatments were subjected to RNA deep sequencing. The total reads and mapping efficiency of each sample are detailed in Supplementary Table 2, and the count of detected genes in each sample is illustrated by a Venn diagram (Fig. 1D). The total number of detected genes in all samples was 28,633, and 18,885 genes were co-expressed. The expression profiles of $\beta$ hCG and GCM1 as measured by RNA-Seq (left panel) showed similar tendency with those examined by qRT-PCR analysis (right panel) of the same samples (Fig. 1E). Principal component analysis (PCA) revealed that samples obtained at $\mathrm{Oh}$ and after 24- and 48-h DMSO treatments formed a distinctive cluster, whereas the expression profiles of FSK-treated samples were different, indicating the informativeness of the RNA-Seq data regarding BeWo cell treatments (Fig. 1F). This result was also confirmed by heatmap hierarchical clustering (Fig. 1G).

\section{Functional analysis of DEGs during FSK-induced fusion of BeWo cells}

DEGs between FSK-treated samples and their corresponding vehicle controls were identified as having a $P<0.001$ and a fold change $\geq 2$. The results shown in Fig. 2A indicate that 856 genes were differentially expressed between samples of FSK at $24 \mathrm{~h}$ (F24h) and DMSO at $24 \mathrm{~h}(\mathrm{D} 24 \mathrm{~h})$ and that 1642 DEGs were identified between samples of FSK at $48 \mathrm{~h}$ (F48h) and
DMSO at $48 \mathrm{~h}$ (D48 h). Moreover, 596 DEGs overlapped. Among these 596 genes, 332 were upregulated and 263 were downregulated, with only 1 gene downregulated at $24 \mathrm{~h}$ but upregulated at $48 \mathrm{~h}$.

To investigate the biological functions of DEGs during BeWo cell fusion, the 260 24h-specific DEGs, 596 common DEGs and 1046 48h-specific DEGs were subjected to GO analysis, as shown in Fig. 2B, C and $\mathrm{D}$ respectively. Notably, cell motion/migration and cytoskeleton organization were all enriched (Fig. 2B, C, D). Interestingly, the terms 'regulation of I-kappaB kinase/NF-kappaB cascade', 'protein oligomerization' and 'cell junction assembly' were only enriched for the 26024 h-specific DEGs (Fig. 2B). The genes involved in regulation of I-kappaB kinase/NF-kappaB cascade were ZDHHC17 (zinc finger, DHHC-type containing 17), TLR4 (toll-like receptor 4), PIM2 (Pim-2 protooncogene), TRIM38 (tripartite motif-containing 38), $\mathrm{RHOH}$ (ras homolog gene family, member $\mathrm{H}$ ) and GJA 1 (gap junction protein, alpha $1,43 \mathrm{kDa}$, also named $C X 43$ ), with the former four decreased and the latter two increased (Supplementary Table 6). As for the 6 genes enriched in protein oligomerization, IDE (insulin-degrading enzyme), SHMT1 (serine hydroxymethyltransferase 1 (soluble)), TP63 (tumor protein p63), TRIM6 (tripartite motifcontaining 6) and $A M F R$ (autocrine motility factor receptor) were downregulated, whereas CX43 was upregulated (Supplementary Table 6). Three genes were enriched in cell junction assembly, including the upregulated $C X 43$ and TNS1 and the downregulated AMOT (angiomotin) (Supplementary Table 6). Interestingly, CX43 was included in each of these three terms.

More biological terms were enriched for the 596 common DEGs and 104648 h-specific DEGs (Fig. 2C, D), including cell cycle, cell proliferation, cell motion, cell apoptosis, cell activation, regulation of phosphorylation, intracellular and cell-cell signaling pathways and cellular and extracellular structure organization. Other terms were also abundantly clustered for the 596 DEGs, such as lipid transport, amino acid transport, calcium ion transport, response to estrogen stimulus, cell differentiation, regulation of cell adhesion, cell fate commitment and regulation of cell morphogenesis involved in differentiation (Fig. 2C).

Among the aforementioned 856 DEGs between F24h and D24h, 461 were upregulated and 395 were downregulated. Among the 1642 DEGs between F48 h and D48h, 879 were increased and 763 were decreased. We termed the previously mentioned DEGs as $24 \mathrm{~h}$-up, $24 \mathrm{~h}$-dn, $48 \mathrm{~h}$-up and $48 \mathrm{~h}-\mathrm{dn}$ respectively. The four groups of DEGs were subjected to GO analysis to show the genes enriched in the related functional processes during BeWo cell fusion. Among the functional processes, the GO term 'syncytium formation by plasma membrane fusion' was uniquely enriched in the $24 \mathrm{~h}-\mathrm{dn}$ DEGs (Fig. 2E). The 3 genes involved in this term were CACNA1S, NEO1 and MYH9, all of which 
have been implicated in the process of myoblast fusion (Seigneurin-Venin et al. 1994, Kang et al. 2004, Swailes et al. 2006). The other GO term most significantly enriched in the $24 \mathrm{~h}$ - $\mathrm{dn}$ group was 'negative regulation of epithelial cell differentiation', and the genes involved were OVOL2 (ovo-like zinc finger 2), NEO1 and MYH9 (Supplementary Table 6). In the 24 h-up group, regeneration and cell junction assembly were clustered uniquely, and lipid localization and collagen metabolic process were clustered significantly. Interestingly, in addition to CD9 and BCL2 (B-cell CLL/lymphoma 2), CX43 and TNS1 were again clustered in the term 'cell junction assembly'. Terms related to muscle cell differentiation, synapse organization, Ras protein signaling transduction and extracellular structure organization were significantly enriched both in the $24 \mathrm{~h}-\mathrm{dn}$ and $48 \mathrm{~h}-\mathrm{dn}$ groups. Amino acid transport, cell-cell signaling, response to estrogen stimulus, antiapoptosis, regulation of muscle cell differentiation and inactivation of mitogen-activated protein kinase (MAPK) activity were clustered most significantly in the $24 \mathrm{~h}$-up and $48 \mathrm{~h}$-up groups. The presence of clusters of cell activation, negative regulation of cell differentiation, cell motion and cell migration in the $24 \mathrm{~h}$-up and $24 \mathrm{~h}-\mathrm{dn}$ DEGs indicate that some genes involved in one process are activated and others are repressed to initiate cell fusion.

\section{Functional enrichment analysis of DEGs according to their expression patterns}

We analyzed the 856 DEGs identified at $24 \mathrm{~h}$ and traced their individual kinetic patterns at $48 \mathrm{~h}$. As determined by a K-means clustering algorithm, these dynamically regulated genes were separated into 6 temporal patterns (Fig. 3), which was programmed in the software 'cluster' under the following parameters: the number of clusters was 6 , the number of runs was 100 , and the method of ' $\mathrm{K}$-means' was used. In patterns $\mathrm{A}, \mathrm{C}$ and $\mathrm{E}$, gene expression levels were repressed at $24 \mathrm{~h}$ after FSK treatment (F24 h vs D24 h) and were then maintained (Fig. 3A), upregulated (Fig. 3C) or decreased (Fig. $3 \mathrm{E}$ ) at $48 \mathrm{~h}$ after FSK treatment (F48 h vs D48 h). In contrast, patterns $\mathrm{B}, \mathrm{D}$ and $\mathrm{F}$ exhibited activated gene expression at F24h, and then were maintained (Fig. 3B), downregulated (Fig. 3D) or increased (Fig. 3F) at F48 h. Unexpectedly, most DEGs were distributed into patterns A (337 genes) and B (389 genes). The functional terms enriched for pattern $A$ included cell migration and adhesion, syncytium formation, positive regulation of cell communication, cytoskeleton and extracellular structure organization and cell fate commitment (Fig. 3A). For pattern B, anti-apoptosis, cell activation, regulation of muscle cell differentiation, calcium ion transport, cell cycle and phosphorylation, lipid transport, actin cytoskeleton organization, cell motion and cellcell signaling were enriched (Fig. 3B). Moreover, 50 and
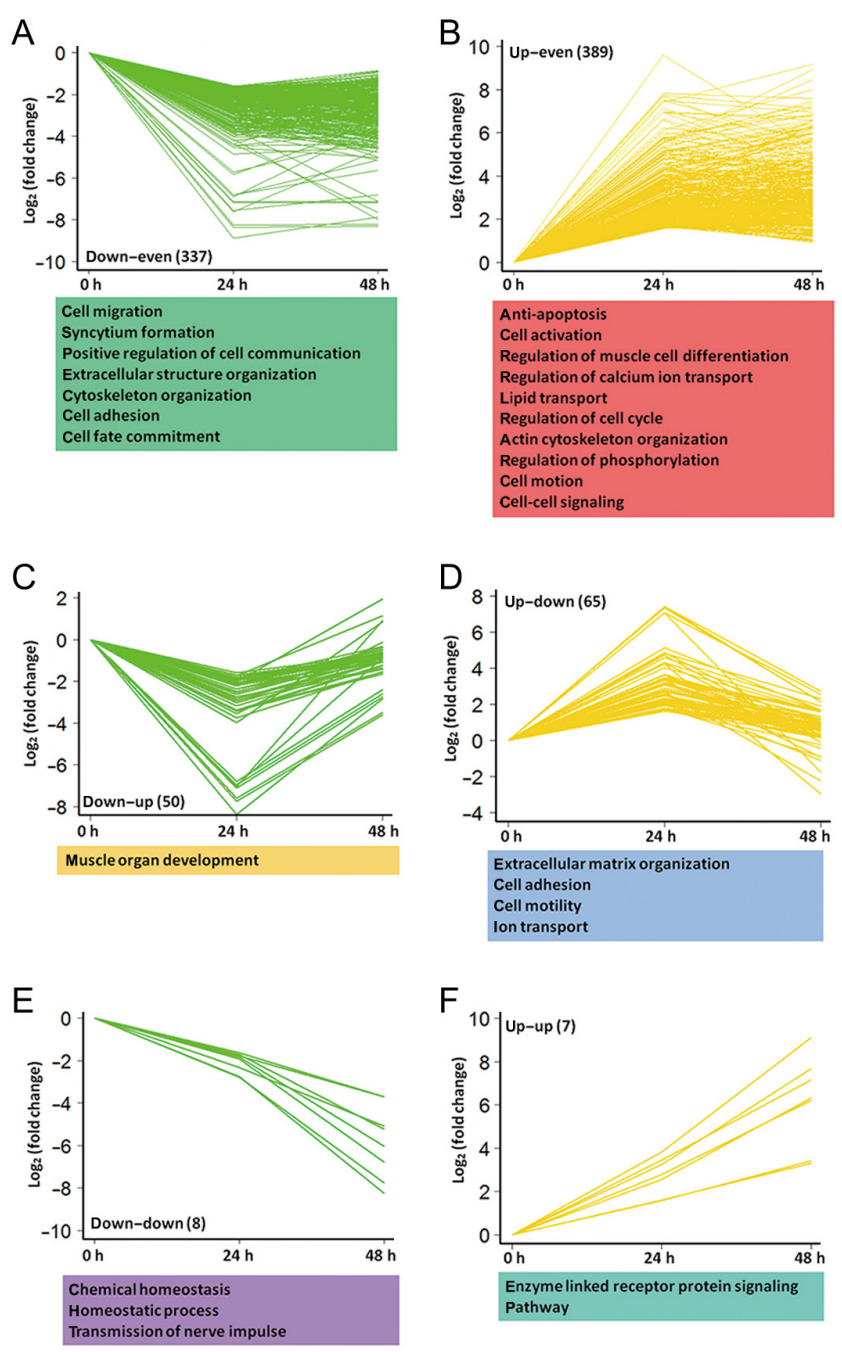

Figure 3 Functional clustering analyses of DEGs based on different expression pattern. The 856 DEGs at $24 \mathrm{~h}$ as shown in Fig. $2 \mathrm{~A}$ were traced individually at $48 \mathrm{~h}$ and separated into 6 dynamic patterns by K-means clustering analysis. (A) Down-even, (B) up-even, (C) down-up, (D) up-down, (E) down-down and (F) up-up. The gene count in each cluster is indicated in parentheses, and the selected GO terms related to BeWo cell-cell fusion are shown under each graph.

65 DEGs were clustered in patterns C and D (Fig. 3C, D) respectively, demonstrating that these genes might function as fusion-repressive or fusion-stimulatory genes at earlier stages of fusion but were controlled at later stages. The genes distributed into each of the 6 patterns are listed in Supplementary Table 6.

\section{GO and KEGG pathway analyses of DEGs during BeWo cell fusion}

Next, all DEGs were subjected to GO functional annotation, and the interaction network of all enriched GO terms was visualized by Cytoscape (Fig. 4A). The GO terms were clustered into 11 overall functional categories: cell proliferation, cell death, cell motion, 


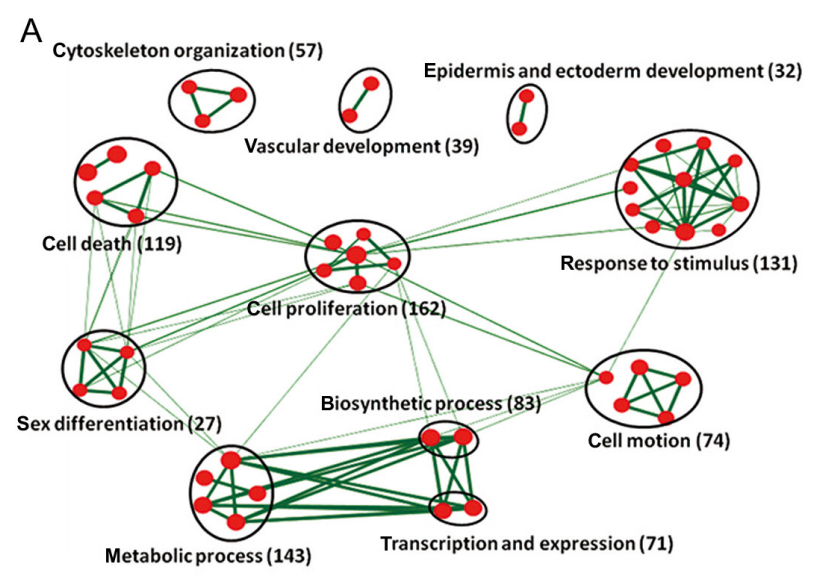

B

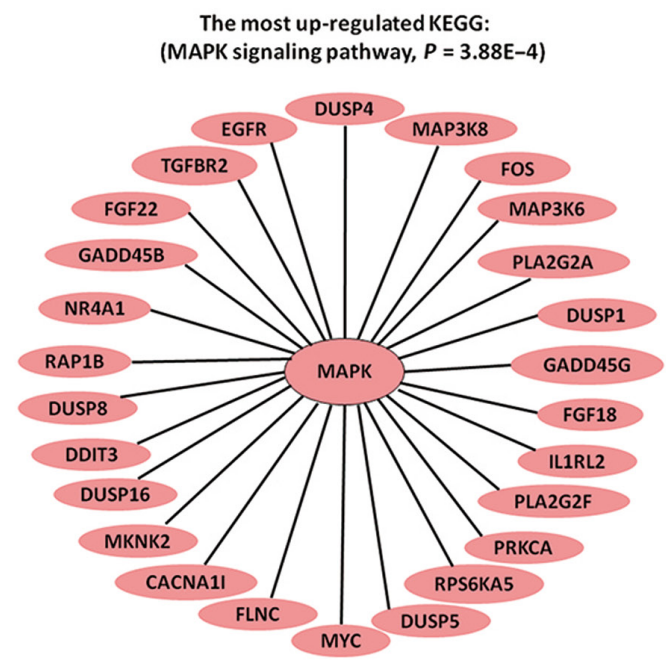

C

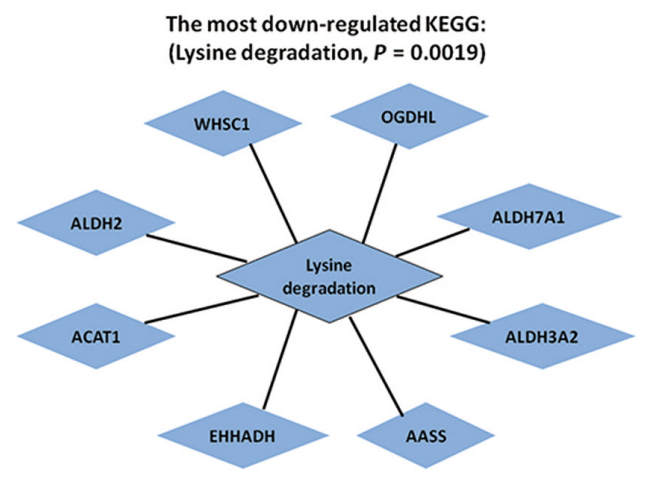

Figure 4 GO and KEGG analysis of all DEGs during BeWo cell fusion. (A) Functional enrichment analysis of all 1902 DEGs shown in Fig. 2A, based on the DAVID GO analysis result. The interaction network was constructed by Cytoscape. The cutoff parameters for the enrichment analysis were $P<0.01$, FDR $q<0.1$, overlap cutoff $>0.5$. GO terms of similar functions were clustered into a single circle and labeled. Gene numbers of each cluster were also indicated. The thickness of the green link represents the number of overlapping genes between red circles. (B) The MAPK signaling pathway was the most significantly upregulated pathway, with 26 upregulated genes, as illustrated by KEGG pathway analysis. $P=3.88 \mathrm{E}-4$. (C) The most significantly downregulated pathway was lysine degradation, with 8 downregulated genes, as illustrated by KEGG pathway analysis. $P=0.0019$. response to stimulus, cytoskeleton organization, vascular development, epidermis and ectoderm development, sex differentiation, transcription and expression, metabolic process and biosynthetic process (Fig. 4A). All pathways clustered by KEGG analysis for total DEGs are shown in Supplementary Table 3, and the most significantly regulated pathway was the MAPK pathway (Supplementary Fig. 1). In addition, the MAPK signaling pathway was the most significantly upregulated pathway, with 26 upregulated genes (Fig. 4B), and the most significantly downregulated pathway was lysine degradation, with 8 downregulated genes (Fig. 4C).

\section{Validation of genes identified by RNA-Seq}

To validate the sequencing data, we assessed the transcript levels of 7 candidate genes as described above (including AMOT, BCL2, CACNA1S, CD9, MYH9, NEO1 and TNS1) involved in BeWo cell fusion and 10 genes randomly selected from all detected genes (including AKR1B10, ASCT2, BASP1, CYP11A1, GPT2, HEXIM1, NUCB2, SQSTM1, S10OP and STMN1) by qRT-PCR in 3 separate FSK-induced BeWo cell samples characterized by a substantial $\beta$-hCG increase (Fig. 5C). Quantitative RT-PCR analysis of the expression patterns of all selected genes (Fig. 5A) revealed results similar to the RNASeq data (Fig. 5B). For the 7 candidate genes, AMOT, CACNA1S, MYH9 and NEO1 were downregulated at $24 \mathrm{~h}$, whereas BCL2,CD9 and TNS1 were upregulated at $24 \mathrm{~h}$. For the 10 randomly selected genes, $A K R 1 B 10$ and ASCT2 were downregulated significantly at $48 \mathrm{~h}$; GPT2, NUCB2 and SQSTM1 were upregulated at $48 \mathrm{~h}$, whereas BASP1, CYP11A1, HEXIM1 and S100P were upregulated at both time points significantly; STMN1 showed similar expression pattern with/without FSK treatment.

We also detected the expression of CACNA1S, CD9, MYH9, NEO1 and TNS1 in human first-trimester placenta villi by immunohistochemistry. CD9, TNS1 and NEO1 were highly expressed in the STB, while CACNA1S and MYH9 were mainly localized in the CTBs (Fig. 5D). To further address the relevance of these genes to human trophoblast syncytialization, the expression of these genes were validated in human primary CTB which were freshly isolated from a term placenta and cultured for $72 \mathrm{~h}$. During the spontaneous syncytialization of human primary CTBs, the expression level of $\beta$-hCG increased substantially (Supplementary Fig. 2). Most of these genes showed similar expression tendencies with those in BeWo cell fusion, like AMOT, CACNA1S, $A K R 1 B 10$ and $A S C T 2$ decreased, and BCL2, CD9, TNS1, BASP1, CYP11A1, GPT2, HEXIM1, NUCB2 and S10OP increased (Supplementary Fig. 2). While MYH9, NEO1 and STMN1 increased, and SQSTM1 decreased in human primary CTB culture, which exhibited different expression pattern compared with those in BeWo cells (Supplementary Fig. 2). 
A

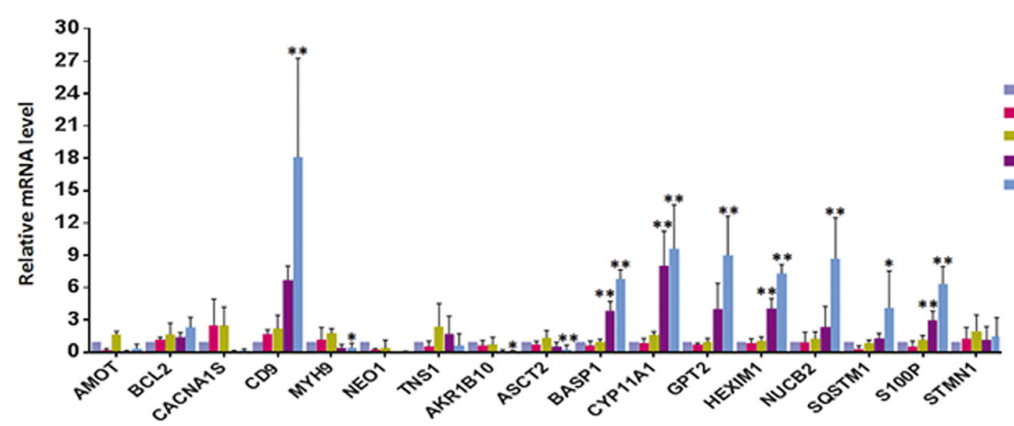

B
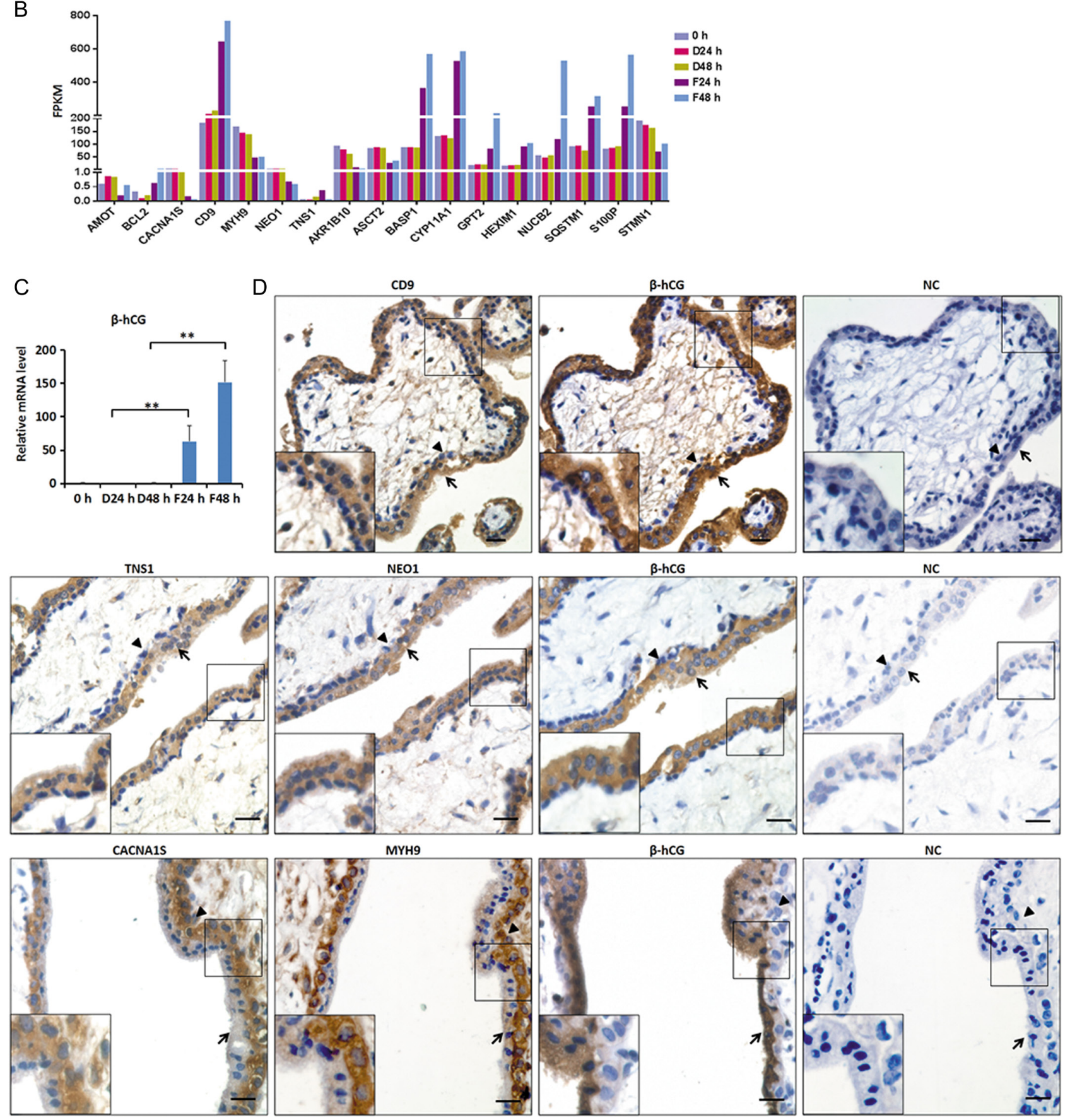

$\beta$-hCG

NC

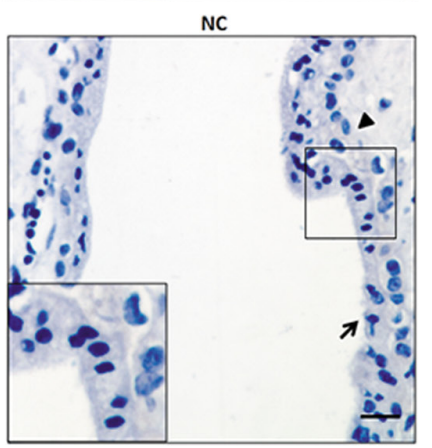


A

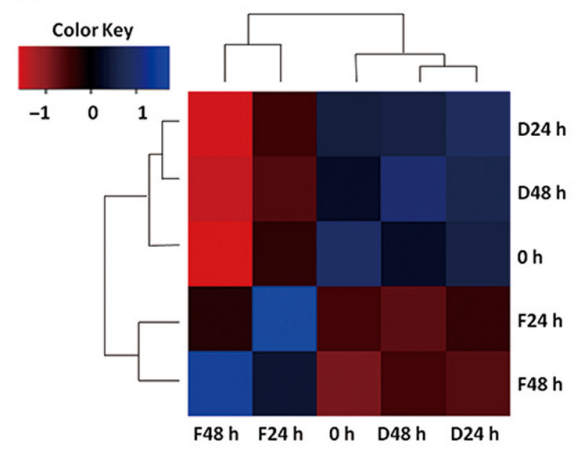

B

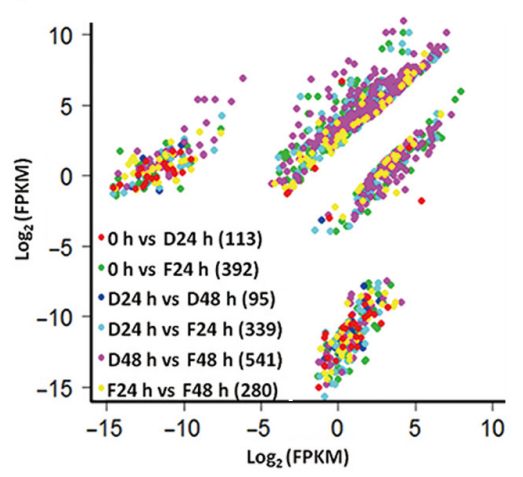

C

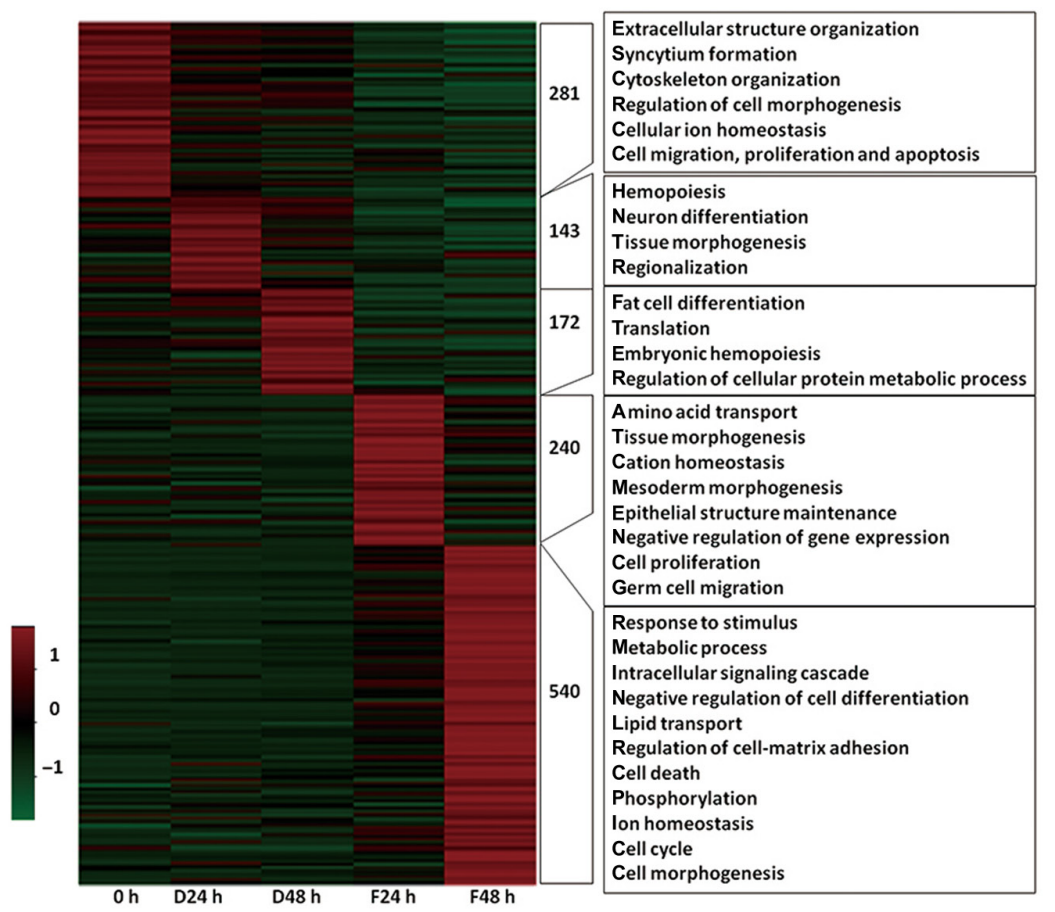

Figure 6 Analyses of the expression profiles of alternative splicing isoforms. (A) A correlation matrix of RNA-Seq samples according to isoform expression level. (B) The scatter plot shows the relative expression levels of differentially expressed isoforms for $0 \mathrm{~h}$ vs D24h, 0 h vs F24h, D24h vs D48h, D24h vs F24h, D48h vs F48h, and F24h vs F48h. Each point represents an isoform highly expressed in either the former (near the horizontal axis) or the latter sample (near the vertical axis). The counts of differentially expressed isoforms are indicated in brackets. Differentially expressed isoforms between two individual samples were defined as having fold changes of no less than 4 and $P$ values of less than 0.01. (C) The heatmap shows the number of differentially expressed isoforms and functions enriched for each highly expressed isoform cluster.

\section{Expression profile analysis of alternative splicing isoforms}

We further analyzed the distributions of isoform expression values in each sample (Supplementary Table 4). In total, 123,200 isoforms were identified. The analysis of isoform expression profiles by correlation matrix suggests a good reliability of the RNA-Seq data, with the 0-h and 24- and 48-h DMSO-treated samples clustering together again (Fig. 6A). Differentially expressed isoforms between two individual samples were determined to have fold changes of no less than 4 and $P$ values of less than 0.01 . The data revealed that 1376 isoforms were differentially expressed during the process of BeWo cell fusion. The number of differentially expressed isoforms between each two indicated samples is shown (Fig. 6B). Fewer differentially expressed isoforms were detected in the samples obtained at $0 \mathrm{~h}$ vs D24h (113 isoforms) and

Figure 5 Validation of the expression patterns of genes identified by RNA-Seq in BeWo cells. The expression patterns of 7 candidate genes (including AMOT, BCL2, CACNA1S, CD9, MYH9, NEO1 and TNS1) involved in BeWo cell fusion and 10 genes randomly selected from all detected genes (including AKR1B10, ASCT2, BASP1, CYP11A1, GPT2, HEXIM1, NUCB2, SQSTM1, S100P and STMN1) were validated by qRT-PCR (A) in separate FSK-induced BeWo cell samples that were simultaneously characterized by substantial $\beta$-hCG induction (C). (B) The expression patterns of genes revealed by RNA-Seq. Data points are shown as the mean \pm S.D. of at least three independent samples. ${ }^{*} P<0.05$; ${ }^{* *} P<0.01$ compared with corresponding controls. (D) Immunohistochemical localization of CACNA1S, CD9, MYH9, NEO1 and TNS1 in human first-trimester placenta villi. CD9, TNS1 and NEO1 were mainly stained in the syncytiotrophoblast (STB). CACNA1S and MYH9 were mainly stained in the cytotrophoblast cells (CTBs). $\beta$-hCG was specifically stained in the STB. NC, negative control. Arrowhead, CTB; arrow, STB. Scale bar $=20 \mu \mathrm{m} . n=3$. 
at D24 $\mathrm{h}$ vs D48 $\mathrm{h}$ (95 isoforms), further supporting the similarities among the samples at $0 \mathrm{~h}, \mathrm{D} 24 \mathrm{~h}$ and D48 $\mathrm{h}$. All differentially expressed isoforms were clustered by heatmap (Fig. 6C), and biological processes were enriched by GO analysis for each highly expressed isoform cluster in the indicated sample. Interestingly, analyses of the expression profiles of alternative splicing isoforms reinforced the importance of GO terms that were revealed in Fig. 2, such as cell migration, cell proliferation, cell cycle, apoptosis, extracellularstructure organization, cell adhesion, cytoskeleton organization, syncytium formation, cell morphogenesis, cellular ion homeostasis and phosphorylation. Four differentially expressed alternative splicing isoforms were randomly selected and the changes of their expression revealed by RNA-Seq were validated in BeWo cells by specific primers via qRT-PCR. The expression of CACNA1S and TTL isoforms decreased, and CCR7 and NOSTRIN increased (Supplementary Fig. 3), further confirming the results from the RNA-Seq.

\section{Discussion}

Although derived from human choriocarcinoma, BeWo cells do, to some extent, reassemble important structural and physiological features of human primary trophoblast (Burres \& Cass 1986, Ramos et al. 2008, Orendi et al. 2010). For example, BeWo cells can form microvilli (Ockleford et al. 1984, Cerneus \& van der Ende 1991) and produce hCG and progesterone (Wasilewski et al. 2012). On the other hand, several molecules, like syncytin-1/-2 (Vargas et al. 2009), GCM1 (Yu et al. 2002, Baczyk et al. 2009) and Furin (Zhou et al. 2013, 2014), have been illustrated to be key players in both BeWo and primary trophoblast cell fusion. Besides those mentioned syncytializationrelated markers, the previous CDNA microarray study of forskolin-induced syncytialization of BeWo cells (Kudo et al. 2004) did help to identify important genes involved in trophoblast fusion, such as CD98 (Kudo \& Boyd 2004, Dalton et al. 2007a,b), or validate important enzymes in syncytiotrophoblast-like CYP11A1 (Lavoie \& King 2009) and genes responded to CAMP in human placental villous explants like placental growth factor (PIGF) (Depoix et al. 2011). Forskolin has been extensively used to trigger fusion of BeWo cells (Chen et al. 2008, Wasilewski et al. 2012, Zhou et al. 2013, Wang et al. 2014). Although forskolin exerts pleiotropic actions on trophoblastic cells as reported by Riddell and coworkers in 2013, at least no significant apoptosis in FSK-treated BeWo cells was observed in our study (Supplementary Fig. 4). Considering the inevitable differences between cell lines and primary cultures, it is conceivable that candidate genes obtained in BeWo cell fusion must be verified in human primary CTBs. In our study, among the expression patterns of several randomly selected genes, most of them in primary CTBs were consistent with those in BeWo cells. Despite that some genes might show moderate changes during BeWo cell fusion, the consistent tendencies of them in the fusion processes of both BeWo cells and primary CTBs suggest their possible roles in trophoblast fusion. We also believe that with the more advanced technology of deep sequencing, this study may also provide insight for more investigations about cell-cell fusion.

In this work, RNA-Seq was used to study the transcriptome during BeWo cell fusion. We detected 28,633 expressed genes, representing more substantial gene expression profiling than early DNA microarray analysis of BeWo cells (Kudo et al. 2004) and human term primary CTBs (Aronow et al. 2001). Notably, thirty genes identified in the previous study (Kudo et al. 2004) were also profiled in the present study, including 20 upregulated DEGs and 10 downregulated DEGs at 24 and/or $48 \mathrm{~h}$. Very recently, Renaud and coworkers also performed a DNA microarray comparing BeWo cells treated with/ without FSK for $24 \mathrm{~h}$ (Renaud et al. 2015); among the top 45 upregulated transcripts during BeWo cell fusion, 32 transcripts were identified in our RNA-Seq study; among the top 45 downregulated transcripts, 22 transcripts were also identified in our study. In addition, Renaud and coworkers show that OVOL1 as the most highly upregulated molecule, which was also selected from the aforementioned study (Kudo et al. 2004) and in our study, functions as an important upstream regulator in human trophoblast cell fusion (Renaud et al. 2015).

We hypothesized that $24 \mathrm{~h}$-specific DEGs maybe more relevant and more responsible for the activation of the fusion machinery compared with $48 \mathrm{~h}$-specific DEGs, and found that the terms 'syncytium formation by plasma membrane fusion' and 'regeneration and cell junction assembly' were uniquely clustered into the $24 \mathrm{~h}$-dn and $24 \mathrm{~h}$-up groups respectively. Indeed, when the 856 genes differentially expressed at $24 \mathrm{~h}$ were individually traced at $48 \mathrm{~h}$, we found that they were distributed into 6 dynamic patterns, whereas most DEGs were enriched in the down-even and upeven patterns, suggesting that fusion-susceptible genes were initiated at earlier stages of fusion and remained stable after most fusion events were accomplished.

Syncytin-2, was shown to be significantly upregulated after 24-h FSK treatment (7.4-fold, $P<0.001)$ and remained relatively stable $(1.7$-fold, $P>0.001)$ at $48 \mathrm{~h}$ according to our RNA-Seq data. MFSD2A was slightly upregulated upon FSK treatment at $24 \mathrm{~h}(4.5$-fold, $P>0.001)$ and increased significantly $(15.3$-fold, $P<0.001)$ at $48 \mathrm{~h}$. These data are consistent with the patterns shown by Chen et al. (2008) and Esnault et al. (2008) respectively. The expression of syncytin-1 and ASCT1 remained constant, whereas ASCT2 decreased significantly $(0.3$-fold, $P<0.001)$ at 
$24 \mathrm{~h}$ and remained unchanged (1.38-fold, $P>0.001)$ at $48 \mathrm{~h}$. As previously reviewed (Dupressoir et al. 2012), syncytin-1 and its receptors appear to be expressed in various types of trophoblast cells in vivo; by contrast, the localization of syncytin-2 and MFSD2A is restricted to CTBs and STB respectively. These expression profiles suggest a putatively major role for syncytin-2 in synergy with syncytin-1 during the fusion of CTBs (Dupressoir et al. 2012). The increasing expression of syncytin-2 and its receptor, as well as the contrary patterns of syncytin- 1 and its receptor(s), revealed by our data imply different modes of action for the two fusogens in human trophoblast fusion.

CACNA1S, NEO1 and MYH9, which were clustered in the $24 \mathrm{~h}$-dn-specific GO term of syncytium formation by plasma membrane fusion in this study, have been implicated as players in myoblast fusion (SeigneurinVenin et al. 1994, Kang et al. 2004, Swailes et al. 2006). CACNA1S encodes the L-type calcium channel CaV1.1, which controls excitation-contraction coupling in skeletal muscle (Wu et al. 2012). Cacna1s mutant mice exhibit hypokalemic periodic paralysis and disruption of the triad junctions (Wu et al. 2012), and the expression of CACNA1S in mutant myotubes of muscular dysgenesis mice improves the morphology of the myotubes (Seigneurin-Venin et al. 1994). NEO1, as a cell cadherin-associated cell-surface receptor of the immunoglobulin superfamily, promotes myoblast fusion into myotubes together with netrin-3 (Kang et al. 2004). MYH9 encodes a non-muscle myosin IIA heavy chain involved in cell motility and cytoskeleton organization, and co-localizes with actin stress fibers (Canobbio et al. 2005). Knockdown of Myh9 in mouse myoblasts represses their differentiation into myotubes due to the inhibition of cell shape change and abnormal cell adhesion (Swailes et al. 2006). However, despite their positive functions in myoblast fusion, these three genes were decreased upon 24-h FSK treatment during BeWo cell fusion, suggesting common features between trophoblast and myoblast fusion whereas distinct manners of action for the 3 genes.

CX43-mediated gap junctional intercellular communication and its interaction with ZO-1 play important roles during human trophoblast fusion (Frendo et al. 2003, Pidoux et al. 2010). Our study showed that CX43 was significantly increased at $24 \mathrm{~h}$ and then remained stable at $48 \mathrm{~h}$. Notably, among all three GO terms that were uniquely clustered in the $24 \mathrm{~h}$-specific DEGs (i.e., regulation of I-kappaB kinase/NF-kappaB cascade, protein oligomerization and cell junction assembly), CX43 was present in all three GO categories. In this respect, our data further reinforced the functional importance of CX43 during trophoblast fusion. The second gene involved in cell junction assembly, TNS1, was upregulated upon FSK treatment at $24 \mathrm{~h}$ and decreased at $48 \mathrm{~h}$. It has been demonstrated that TNS1 as a focal adhesion and an actin-binding protein promotes cell migration (Chen et al. 2002) and participates in actin organization through multiple actin-binding sites (Lo et al. 1994). Therefore, during the early stage of BeWo cell fusion, TNS1 may play a role in cell adhesion and cytoskeletal organization. The third gene involved in cell junction assembly is AMOT, a member of the motin family which was first identified in the placental endothelial cells of capillaries and larger vessels as a binding protein of angiostatin (Troyanovsky et al. 2001). It can increase endothelial cell motility and is localized at the leading edge of migrating cells (Troyanovsky et al. 2001). AMOT can also recruit ZO-1 to actin stress fibers, which plays a central role in cell adhesion and morphogenesis (Bratt et al. 2005).

In addition to CX43, TNS1 and AMOT, CD9 and $B C L 2$ were also clustered in the process of cell junction assembly and were activated at $24 \mathrm{~h}$. CD9 is a member of the tetraspanin family and functions with other cell-surface proteins as a component of multimeric complexes. CD9 has been demonstrated to facilitate myoblast fusion (Tachibana \& Hemler 1999) and sperm-egg fusion (Kaji et al. 2000, Miyado et al. 2000). During FSK-induced BeWo cell fusion, CD9 can increase GCM1 and syncytin-1 expression via the cAMP/PKA signaling pathway (Muroi et al. 2009). It has been reported that the apoptotic cascade in CTBs favors syncytial fusion, and that the anti-apoptotic proteins $\mathrm{Bcl} 2$ and $\mathrm{Mcl}-1$ serve to control excessive progression along the apoptotic pathway (Huppertz et al. 1998). On the other hand, Bcl2 and Mcl-1 are not found in the areas around syncytial sprouts in STB, suggesting that they are also involved in the maintenance of STB homeostasis to prevent the overshedding of dying placental trophoblasts into maternal circulation (Huppertz et al. 1998). Interestingly, our data indicate that it is also involved in STB formation.

During preparation of this manuscript, a study by Shankar and coworkers using RNA-Seq, genome-scale DNA methylation and ChIP-seq to analyze transcriptomics and epigenomics during syncytialization of BeWo cells was published online (Shankar et al. 2015). Their RNA-Seq analysis revealed alterations in approximately 3000 genes over 3 days of FSK treatment. Key biological processes such as cell differentiation and response to steroid hormone were enriched in both their study and ours. More importantly, the authors identified several previously unrecognized signaling pathways and genes involved in syncytialization. Most of these, such as MAPK and TGF- $\beta$ signaling, MMP9, MMP11, SGK1, TRPV2 and $B C L 2$, correspond with our results. However, other candidate genes discussed in their study, such as $A H R, J U N B, L T B P 1$ and MMP2, were not identified in the present study, probably due to differences in the treatment of BeWo cells. Their cells were plated 
at approximately $90 \%$ confluence and then subjected to FSK treatment. Comparisons at 24, 48 and $72 \mathrm{~h}$ after FSK treatment were conducted relative to the 0-h control. In summary, we have provided a detailed analysis of transcriptional profile during BeWo cell fusion. We detected 28,633 genes, of which 1902 transcripts were differentially expressed between FSK treatments and their corresponding vehicle controls. Terms such as syncytium formation, cell junction assembly, cell fate commitment, calcium ion transport, regulation of epithelial cell differentiation and cell morphogenesis involved in differentiation were regulated during BeWo cell fusion. This study also identified new candidate trophoblast fusionrelated players, including CACNA1S, NEO1, MYH9, TNS1, AMOT, CD9 and BCL2, to previously studied functions. Most DEGs were classified into down-even and up-even patterns by a K-means algorithm, suggesting that the fusion machinery was activated at an early stage and remained stable after major fusion events had been accomplished. Further utilization of these data will be critical for understanding the causative mechanisms of syncytialization and for uncovering new fusogenic molecules and transcriptional factors.

\section{Supplementary data}

This is linked to the online version of the paper at http://dx.doi. org/10.1530/REP-16-0343.

\section{Declaration of interest}

The authors declare that there is no conflict of interest that could be perceived as prejudicing the impartiality of the research reported.

\section{Funding}

This work was supported by the Major Program of National Natural Science Foundation of China (NSFC) (grant number 81490741); and a grant from NSFC (grant number 31271603). HY Lin is a recipient of the National Excellent Young Scientist supported by NSFC (grant number 81322008 ).

\section{Acknowledgements}

The authors thank Dr Yun-Gui Yang from Beijing Institute of Genomics, Chinese Academy of Sciences and Dr Xiaolong Cui from Institute of Zoology, Chinese Academy of Sciences for their help.

\section{References}

Aronow BJ, Richardson BD \& Handwerger S 2001 Microarray analysis of trophoblast differentiation: gene expression reprogramming in key gene function categories. Physiological Genomics 6 105-116.
Baczyk D, Drewlo S, Proctor L, Dunk C, Lye S \& Kingdom J 2009 Glial cell missing-1 transcription factor is required for the differentiation of the human trophoblast. Cell Death and Differentiation 16 719-727. (doi:10.1038/cdd.2009.1)

Blaise S, de Parseval N, Benit L \& Heidmann T 2003 Genomewide screening for fusogenic human endogenous retrovirus envelopes identifies syncytin 2, a gene conserved on primate evolution. PNAS $\mathbf{1 0 0}$ 13013-13018. (doi:10.1073/pnas.2132646100)

Blond JL, Beseme F, Duret L, Bouton O, Bedin F, Perron H, Mandrand B \& Mallet F 1999 Molecular characterization and placental expression of HERV-W, a new human endogenous retrovirus family. Journal of Virology 73 1175-1185.

Blond JL, Lavillette D, Cheynet V, Bouton O, Oriol G, Chapel-Fernandes S, Mandrand B, Mallet F \& Cosset FL 2000 An envelope glycoprotein of the human endogenous retrovirus HERV-W is expressed in the human placenta and fuses cells expressing the type D mammalian retrovirus receptor. Journal of Virology 74 3321-3329. (doi:10.1128/JVI.74.7.33213329.2000)

Bratt A, Birot O, Sinha I, Veitonmaki N, Aase K, Ernkvist M \& Holmgren L 2005 Angiomotin regulates endothelial cell-cell junctions and cell motility. Journal of Biological Chemistry 280 34859-34869. (doi:10.1074/jbc.M503915200)

Burres NS \& Cass CE 1986 Density-dependent inhibition of expression of syncytiotrophoblastic markers by cultured human choriocarcinoma (BeWo) cells. Journal of Cellular Physiology 128 375-382. (doi:10.1002/ jcp.1041280305)

Canobbio I, Noris P, Pecci A, Balduini A, Balduini CL \& Torti M 2005 Altered cytoskeleton organization in platelets from patients with MYH9related disease. Journal of Thrombosis and Haemostasis 3 1026-1035. (doi:10.1111/j.1538-7836.2005.01244.x)

Cerneus DP \& van der Ende A 1991 Apical and basolateral transferrin receptors in polarized BeWo cells recycle through separate endosomes. Journal of Cell Biology 114 1149-1158. (doi:10.1083/ jcb.114.6.1149)

Chen EH \& Olson EN 2005 Unveiling the mechanisms of cell-cell fusion. Science 308 369-373. (doi:10.1126/science.1104799)

Chen H, Duncan IC, Bozorgchami H \& Lo SH 2002 Tensin1 and a previously undocumented family member, tensin2, positively regulate cell migration. PNAS 99 733-738. (doi:10.1073/pnas.022518699)

Chen CP, Chen LF, Yang SR, Chen CY, Ko CC, Chang GD \& Chen H 2008 Functional characterization of the human placental fusogenic membrane protein syncytin 2. Biology of Reproduction 79 815-823. (doi:10.1095/ biolreprod.108.069765)

Cross JC, Werb Z \& Fisher SJ 1994 Implantation and the placenta: key pieces of the development puzzle. Science 266 1508-1518. (doi:10.1126/science.7985020)

Dalton P, Christian HC, Redman CW, Sargent IL \& Boyd CA 2007a Differential effect of cross-linking the CD98 heavy chain on fusion and amino acid transport in the human placental trophoblast (BeWo) cell line. Biochimica et Biophysica Acta 1768 401-410. (doi:10.1016/j. bbamem.2006.11.020)

Dalton P, Christian HC, Redman CW, Sargent IL \& Boyd CA 2007 b Membrane trafficking of CD98 and its ligand galectin 3 in BeWo cells implication for placental cell fusion. FEBS Journal 274 2715-2727. (doi:10.1111/j.1742-4658.2007.05806.x)

Depoix C, Tee MK \& Taylor RN 2011 Molecular regulation of human placental growth factor (PIGF) gene expression in placental villi and trophoblast cells is mediated via the protein kinase a pathway. Reproductive Sciences 18 219-228. (doi:10.1177/ 1933719110389337)

Dupressoir A, Lavialle C \& Heidmann T 2012 From ancestral infectious retroviruses to bona fide cellular genes: role of the captured syncytins in placentation. Placenta 33 663-671. (doi:10.1016/j. placenta.2012.05.005)

Esnault C, Priet S, Ribet D, Vernochet C, Bruls T, Lavialle C, Weissenbach J \& Heidmann T 2008 A placenta-specific receptor for the fusogenic, endogenous retrovirus-derived, human syncytin-2. PNAS 105 17532-17537. (doi:10.1073/pnas.0807413105)

Forbes K, Westwood M, Baker PN \& Aplin JD 2008 Insulin-like growth factor I and II regulate the life cycle of trophoblast in the developing human placenta. American Journal of Physiology: Cell Physiology 294 C1313-C1322. (doi:10.1152/ajpcell.00035.2008) 
Frendo JL, Cronier L, Bertin G, Guibourdenche J, Vidaud M, Evain-Brion D \& Malassine A 2003 Involvement of connexin 43 in human trophoblast cell fusion and differentiation. Journal of Cell Science 116 3413-3421. (doi:10.1242/jcs.00648)

Gauster M, Moser G, Orendi K \& Huppertz B 2009 Factors involved in regulating trophoblast fusion: potential role in the development of preeclampsia. Placenta 30 (Supplement A) S49-S54. (doi:10.1016/j. placenta.2008.10.011)

Gerbaud P, Pidoux G, Guibourdenche J, Pathirage N, Costa JM, Badet J, Frendo JL, Murthi P \& Evain-Brion D 2011 Mesenchymal activin-A overcomes defective human trisomy 21 trophoblast fusion. Endocrinology 152 5017-5028. (doi:10.1210/en.2011-1193)

Huppertz B, Frank HG, Kingdom JC, Reister F \& Kaufmann P 1998 Villous cytotrophoblast regulation of the syncytial apoptotic cascade in the human placenta. Histochemistry and Cell Biology 110 495-508. (doi:10.1007/s004180050311)

Kaji K, Oda S, Shikano T, Ohnuki T, Uematsu Y, Sakagami J, Tada N, Miyazaki S \& Kudo A 2000 The gamete fusion process is defective in eggs of Cd9-deficient mice. Nature Genetics 24 279-282. (doi:10.1038/73502)

Kang JS, Yi MJ, Zhang W, Feinleib JL, Cole F \& Krauss RS 2004 Netrins and neogenin promote myotube formation. Journal of Cell Biology $\mathbf{1 6 7}$ 493-504. (doi:10.1083/jcb.200405039)

Kudo Y \& Boyd CA 2004 RNA interference-induced reduction in CD98 expression suppresses cell fusion during syncytialization of human placental BeWo cells. FEBS Letters 577 473-477. (doi:10.1016/j. febslet.2004.10.047)

Kudo Y, Boyd CA, Sargent IL, Redman CW, Lee JM \& Freeman TC 2004 An analysis using DNA microarray of the time course of gene expression during syncytialization of a human placental cell line (BeWo). Placenta 25 479-488. (doi:10.1016/j.placenta.2003.12.001)

Lavillette D, Marin M, Ruggieri A, Mallet F, Cosset FL \& Kabat D 2002 The envelope glycoprotein of human endogenous retrovirus type $W$ uses a divergent family of amino acid transporters/cell surface receptors. Journal of Virology 76 6442-6452. (doi:10.1128/JVI.76.13.64426452.2002)

Lavoie HA \& King SR 2009 Transcriptional regulation of steroidogenic genes: STARD1, CYP11A1 and HSD3B. Experimental Biology and Medicine 234 880-907. (doi:10.3181/0903-MR-97)

Leduc K, Bourassa V, Asselin E, Leclerc P, Lafond J \& Reyes-Moreno C 2012 Leukemia inhibitory factor regulates differentiation of trophoblastlike BeWo cells through the activation of JAK/STAT and MAPK3/1 MAP kinase-signaling pathways. Biology of Reproduction 86 54. (doi:10.1095/ biolreprod.111.094334)

Leisser C, Saleh L, Haider S, Husslein H, Sonderegger S \& Knofler M 2006 Tumour necrosis factor-alpha impairs chorionic gonadotrophin betasubunit expression and cell fusion of human villous cytotrophoblast. Molecular Human Reproduction 12 601-609. (doi:10.1093/molehr/ gal066)

Li Y, Zheng R, Wang R, Lu X, Zhu C, Lin HY, Wang H, Yu X \& Fu J 2015 Involvement of nephrin in human placental trophoblast syncytialization. Reproduction 149 339-346. (doi:10.1530/REP-14-0424)

Liang CY, Wang LJ, Chen CP, Chen LF, Chen YH \& Chen H 2010 GCM1 regulation of the expression of syncytin 2 and its cognate receptor MFSD2A in human placenta. Biology of Reproduction 83 387-395. (doi:10.1095/biolreprod.110.083915)

Lo SH, Janmey PA, Hartwig JH \& Chen LB 1994 Interactions of tensin with actin and identification of its three distinct actin-binding domains. Journal of Cell Biology 125 1067-1075. (doi:10.1083/ jcb.125.5.1067)

Mi S, Lee X, Li X, Veldman GM, Finnerty H, Racie L, LaVallie E, Tang XY, Edouard P, Howes S et al. 2000 Syncytin is a captive retroviral envelope protein involved in human placental morphogenesis. Nature 403 785-789. (doi:10.1038/35001608)

Miyado K, Yamada G, Yamada S, Hasuwa H, Nakamura Y, Ryu F, Suzuki K, Kosai K, Inoue K, Ogura A et al. 2000 Requirement of CD9 on the egg plasma membrane for fertilization. Science 287 321-324. (doi:10.1126/ science.287.5451.321)

Morrish DW, Bhardwaj D, Dabbagh LK, Marusyk H \& Siy O 1987 Epidermal growth factor induces differentiation and secretion of human chorionic gonadotropin and placental lactogen in normal human placenta. Journal of Clinical Endocrinology and Metabolism 65 1282-1290. (doi:10.1210/ jcem-65-6-1282)
Muroi Y, Sakurai T, Hanashi A, Kubota K, Nagaoka K \& Imakawa K 2009 CD9 regulates transcription factor GCM1 and ERVWE1 expression through the CAMP/protein kinase A signaling pathway. Reproduction 138 945-951. (doi:10.1530/REP-09-0082)

Ockleford CD, Dearden L \& Badley RA 1984 Syncytioskeletons in choriocarcinoma in culture. Journal of Cell Science 66 1-20.

Orendi K, Gauster M, Moser G, Meiri H \& Huppertz B 2010 The choriocarcinoma cell line BeWo: syncytial fusion and expression of syncytium-specific proteins. Reproduction 140 759-766. (doi:10.1530/ REP-10-0221)

Pidoux G, Gerbaud P, Gnidehou S, Grynberg M, Geneau G, Guibourdenche J, Carette D, Cronier L, Evain-Brion D, Malassine A et al. 2010 ZO-1 is involved in trophoblastic cell differentiation in human placenta. American Journal of Physiology: Cell Physiology 298 C1517-C1526. (doi:10.1152/ajpcell.00484.2008)

Potgens AJ, Drewlo S, Kokozidou M \& Kaufmann P 2004 Syncytin: the major regulator of trophoblast fusion? Recent developments and hypotheses on its action. Human Reproduction Update 10 487-496. (doi:10.1093/humupd/dmh039)

Ramos AJ, Cantero MR, Zhang P, Raychowdhury MK, Green A, MacPhee D \& Cantiello HF 2008 Morphological and electrical properties of human trophoblast choriocarcinoma, BeWo cells. Placenta 29 492-502. (doi:10.1016/j.placenta.2008.02.013)

Renaud SJ, Chakraborty D, Mason CW, Rumi MA, Vivian JL \& Soares MJ 2015 OVO-like 1 regulates progenitor cell fate in human trophoblast development. PNAS 112 E6175-E6184. (doi:10.1073/ pnas.1507397112)

Riddell MR, Winkler-Lowen B, Jiang Y, Davidge ST \& Guilbert LJ 2013 Pleiotropic actions of forskolin result in phosphatidylserine exposure in primary trophoblasts. PLOS ONE 8 e81273. (doi:10.1371/journal. pone.0081273)

Ruebner M, Langbein M, Strissel PL, Henke C, Schmidt D, Goecke TW, Faschingbauer F, Schild RL, Beckmann MW \& Strick R 2012 Regulation of the human endogenous retroviral Syncytin- 1 and cell-cell fusion by the nuclear hormone receptors PPARgamma/RXRalpha in placentogenesis. Journal of Cellular Biochemistry 113 2383-2396. (doi:10.1002/ jcb.24110)

Seigneurin-Venin S, Song M, Pincon-Raymond M, Rieger F \& Garcia L 1994 Restoration of normal ultrastructure after expression of the alpha 1 subunit of the L-type Ca2+ channel in dysgenic myotubes. FEBS Letters 342 129-134. (doi:10.1016/0014-5793(94)80486-9)

Shankar K, Kang P, Zhong Y, Borengasser SJ, Wingfield C, Saben J, Gomez-Acevedo H \& Thakali KM 2015 Transcriptomic and epigenomic landscapes during cell fusion in BeWo trophoblast cells. Placenta $\mathbf{3 6}$ 1342-1351. (doi:10.1016/j.placenta.2015.10.010)

Shibukawa Y, Yamazaki N, Kumasawa K, Daimon E, Tajiri M, Okada Y, Ikawa M \& Wada Y 2010 Calponin 3 regulates actin cytoskeleton rearrangement in trophoblastic cell fusion. Molecular Biology of the Cell 21 3973-3984. (doi:10.1091/mbc.E10-03-0261)

Swailes NT, Colegrave M, Knight PJ \& Peckham M 2006 Non-muscle myosins $2 \mathrm{~A}$ and $2 \mathrm{~B}$ drive changes in cell morphology that occur as myoblasts align and fuse. Journal of Cell Science 119 3561-3570. (doi:10.1242/jcs.03096)

Tachibana I \& Hemler ME 1999 Role of transmembrane 4 superfamily (TM4SF) proteins CD9 and CD81 in muscle cell fusion and myotube maintenance. Journal of Cell Biology 146 893-904. (doi:10.1083/ jcb.146.4.893)

Troyanovsky B, Levchenko T, Mansson G, Matvijenko O \& Holmgren L 2001 Angiomotin: an angiostatin binding protein that regulates endothelial cell migration and tube formation. Journal of Cell Biology 152 1247-1254. (doi:10.1083/jcb.152.6.1247)

Vargas A, Moreau J, Landry S, LeBellego F, Toufaily C, Rassart E, Lafond J \& Barbeau B 2009 Syncytin-2 plays an important role in the fusion of human trophoblast cells. Journal of Molecular Biology 392 301-318. (doi:10.1016/j.jmb.2009.07.025)

Wang R, Dang YL, Zheng R, Li Y, Li W, Lu X, Wang LJ, Zhu C, Lin HY \& Wang H 2014 Live cell imaging of in vitro human trophoblast syncytialization. Biology of Reproduction 90 117. (doi:10.1095/ biolreprod.113.114892)

Wasilewski M, Semenzato M, Rafelski SM, Robbins J, Bakardjiev Al \& Scorrano L 2012 Optic atrophy 1-dependent mitochondria! remodeling controls steroidogenesis in trophoblasts. Current Biology 22 1228-1234. (doi:10.1016/j.cub.2012.04.054) 
Wu F, Mi W, Hernandez-Ochoa EO, Burns DK, Fu Y, Gray HF, Struyk AF, Schneider MF \& Cannon SC 2012 A calcium channel mutant mouse model of hypokalemic periodic paralysis. Journal of Clinical Investigation 122 4580-4591. (doi:10.1172/JCI66091)

Yu C, Shen K, Lin M, Chen P, Lin C, Chang GD \& Chen H 2002 GCMa regulates the syncytin-mediated trophoblastic fusion. Journal of Biological Chemistry 277 50062-50068. (doi:10.1074/jbc.M209316200)

Zhou Z, Zhang Q, Lu X, Wang R, Wang H, Wang YL, Zhu C, Lin HY \& Wang H 2013 The proprotein convertase furin is required for trophoblast syncytialization. Cell Death and Disease 4 e593. (doi:10.1038/ cddis.2013.106)

Zhou Z, Wang $R$, Yang $X$, Lu XY, Zhang $Q$, Wang $Y L$, Wang $\mathbf{H}$, Zhu C, Lin HY \& Wang H 2014 The cAMP-responsive element binding protein (CREB) transcription factor regulates furin expression during human trophoblast syncytialization. Placenta 35 907-918. (doi:10.1016/j.placenta.2014.07.017)

Received 27 June 2016

First decision 10 August 2016

Revised manuscript received 26 September 2016

Accepted 14 October 2016 